\title{
LO POPULAR EN LA PINTURA DE FRIDA KAHLO
}

\section{Por Teresa del Conde}

Dos razones me impulsan a tratar este tema. La primera está determinada por la redacción de una biografía sobre Frida Kahlo que he llevado a cabo recientemente. $\mathrm{El}$ reconstruir su vida a través de lo que se ha dicho de ella, de la lectura de su diario y de cartas a ella dirigidas, y sobre todo, la observación de sus pinturas, me ha permitido tener una idea global de su personalidad, que como es bien sabido, quedó intensamente disuelta en su obra. El universo de Frida se reduce a ella misma, principio y fin de todos sus pensamientos y afanes, de aquí que salvo raras excepciones (los retratos que dejó de otras gentes, por ejemplo), todo lo que hizo pertenezca en una $u$ otra forma al género del autorretrato, inclusive obras en las que su persona física está ausente.

La segunda razón se refiere a la celebración del coloquio sobre la dicotomía entre el arte culto y el arte popular en la ciudad de Zacatecas. Este evento ha actuado como un fuerte estímulo que hace abrir más los ojos ante la problemática que plantea la interdependencia artística. Frida Kahlo es un caso prototípico de pintora "culta" que abreva deliberadamente en fuentes populares, sin que su proceder se asemeje propiamente al del pintor que es naïve por naturaleza. Mi intención en este ensayo es analizar tal aspecto de la pintura de Frida a través de unos cuantos ejemplos, poniendo de manifiesto a la vez las ligas que su pintura tiene con la corriente surrealista.

A mi modo de ver la expresión popular que existe en la pintura de Frida Kahlo, se da inicialmente a partir de una temprana elección que ella hace respondiendo a circunstancias de dos tipos: por un lado a su escaso entrenamiento académico. Como en buena medida fue autodidacta, 1 el dominio de su oficio fue alcanzado paulatinamente. Al principio de su carrera como pintora ella se dio cuenta de las limitaciones que tenía en cuanto a técnica y fue lo suficientemente inteligente y sensible como para escoger una modalidad expresiva acorde a sus posibilidades. El otro tipo de circunstancias está referido a sus condiciones existenciales, su infancia y adolescencia transcurridos en el ambiente pueblerino de Coyoacán, sitio donde funcionó desde 1921 una

1 Cuando Frida Kahlo estudiaba medicina en la Escuela Nacional Preparatoria, al mismo tiempo asistía a unas clases de grabado impartidas por Fernando Fernández. Ambas actividades quedaron inter umpidas a partir del accidente. 
importante escuela de pintura al aire libre. De otra parte, tuvo un contacto temprano con la imagineria religiosa de carácter popular (su madre era recalcitrantemente católica) y también vivió muy de cerca el nacimiento del muralismo mexicano cuando era estudiante en la Escuela Nacional Preparatoria. A mi parecer, estos factores tomados en conjunto, determinan la elección de una forma de expresión que pasando por diversas fases evolutivas llegan a conformar el estilo altamente individual de esta pintora.

A raíz del accidente que Frida sufrió en septiembre de 1926, se decidió su vocación de artista. La expresión popular en sus primeras pinturas, alterna con intentos de estilización a la europea que resultan fallidos. Un cuadro es representativo de este titubeo: el retrato de Alicia Galant, fechado en 1927. Si se observa el cuadro y se le relaciona con otros realizados en ese año y en los dos subsecuentes, salta a la vista la falta de concordancia con la manera que vendrá a ser la propia de Frida. Dominan los tonos oscuros, el trazo es extremadamente cuidadoso y a la vez, torpe, y algo muy importante: ella está ausente de esta pintura, no porque no contenga su imagen, sino porque no incluye en el cuadro ni uno solo de los elementos que le son gratos. Aparte de eso, la composición cromática es opuesta a la que encontramos en la mayoría de sus obras posteriores. Existen dos retratos más, uno de su hermana Cristina y otro de ella misma, que tienen características similares y que acaso acusan influencia de Roberto Montenegro, pero que no llegan a tener esa pretensión "elegante" que evidencía un "quiero y no puedo" por parte de la pintora. En este caso la obra es naive por torpeza.

En cambio el Autorretrato con aeroplano de 1929 es una obra fresca, compuesta con soltura. Si tiene las deficiencias propias de un oficio incipientemente adquirido, éstas quedan justificadas por el carácter deliberadamente popular que tiene la pintura. Frida se siente a sus anchas representándose frontalmente, muy tiesa y con un cuello larguísimo. La enmarca un cortinaje verde, simétrico, amarrado toscamente con unos cordeles gruesos. A su lado se encuentra una extraña columna salomonóica que sostiene un reloj despertador; el aeroplano de juguete vuela en el espacio abierto que la ventana deja libre. Detalles como el pesado collar y los aretes largos ayudan a balancear la composición en la que ya se advierte una sofisticación muy consciente dentro de un tipo de expresión popular. En este cuadro las deficiencias de oficio quedan, por asf decirlo, enmascaradas.

Cuán diferente es el hermoso autorretrato a lápiz que Frida dedica 
a Marte R. Gómez 15 años después. Aquí no es la factura lo que recuerda la obra popular; dado que el dibujo es impecable y refinado, la inclusión de una cartela en el extremo superior izquierdo que ostenta la dedicatoria; la cinta se desfleca en un extremo confundiéndose con el pelo de Frida y por el otro se metamorfosea en una flor cuyas raices se complican con otros elementos dando al conjunto un matiz surreal. Frida ha llegado plenamente a dominar su oficio y persiste en conservar motivos decorativos de procedencia popular, que aportan a la composición un estudiado esteticismo.

El primer artículo serio que he encontrado sobre la pintura de Frida Kahlo, se debe al biógrafo de Diego Rivera, Bertram D. Wolfe, quien publicó en Vogue ${ }^{2}$ el año de 1938 una presentación como antecedente a la exposición individual de varias pinturas de Frida, en la Galerfa de Julien Lévy en Nueva York.

Wolfe, que no es propiamente crítico de arte, percibe que Frida "selecciona objetos dignos de rememorarse", estos objetos provienen en la mayoría de las ocasiones de la imaginería popular. Escoge juguetes (judas, muñecos), implementos domésticos (petates, muebles, objetos), motivos fitomórficos, ornamentos personales, motivos decorativos, etcétera, y los combina unos con otros en vías de darles un significado que está en relación con un mensaje estrictamente personal que ella quiere transmitir. La presencia de estos objetos puede ser simbólica o simplemente ornamental, pero en todo caso, siempre obedece a una razón lógica aun y cuando el conjunto presentado en el cuadro sea de carácter fantástico o irreal. Esta característica es percibida por Wolfe como ejemplo de un "surrealismo naïve", término que acuña para explicar la esperanza ingenua con que Frida se contempla a sí misma y la fantasía a la vez alegre y melancólica con que realiza su selección de motivos. $\mathrm{El}$ término, a mi modo de ver, es afortunado; las relaciones entre el proceso surreal y el modo de proceder del pintor naive desde luego que son considerables. Un ejemplo característico lo tenemos en la pintura de exvotos. En ellos la dualidad existencia-destrucción, angustia y amenaza que se canalizan en posibilidad de salvación, plantean un enigma al situar en un mismo plano lo posible y lo imposible. Esta dualidad se codea con la ambigüedad surrealista.

Paul Westheim ${ }^{3}$ e Ida Rodríguez Prampolini * estudian el nexo de

2 Bertram D. Wolfe. "Frida Kahlo". Vogue, New York, Sept. 1938, pp. 12-19.

3 Paul Westheim. "Frida Kahlo", Novedades, México, 10 de junio de 1951.

4 Ida Rodríguez Prampolini. El surrealismo y el arte fantístico de México. Instituto de Investigaciones Estéticas, UNAM. México, 1969, pp. 60-61. 
la pintura de Frida con el exvoto popular, llegando ambos a conclusiones similares. Westheim, apoyándose en Roberto Montenegro, afirma que Frida coloca en una zona "situada más ellá del tiempo y del espacio, elementos heterogéneos vinculados en una relación interna, no exterior". Este proceder, a su juicio, tiene mucho de los retablos e implica "la esperanza de que en este mundo sea posible el milagro". Ida Rodríguez afina la observación de Westheim cuando dice que:

Lo que Frida recoge del alma popular del exvoto, es además de esta afirmación vital (expresada por Westheim), la sinceridad, el infantilismo de las formas y la realización de una verdad dicha de tal manera que parece una mentira, porque no hay límite que demarque el mundo de lo real, de lo natural y objetivo, del mundo de la invención y el símbolo...

Respecto a esto último, es preciso aclarar lo siguiente: en el exvoto está expresada esa verdad subjetiva que parece mentira a los ojos incrédulos o "cultos", pero en Frida no sucede lo mismo. Sus obras, con todo y ser fantásticas, tienen una estructura interna perfectamente lógica, no hay dos planos, uno posible y el otro no. Hay un solo plano producto de lo que ella quiere comunicar, o repetirse a sí misma, que es siempre complicado y subjetivo. En el retablo es tan real el hecho acontecido como la intervención ultraterrena que hace posible el milagro. En Frida no hay milagro y por lo tanto, tampoco la acción de gracias, que constituye la razón de ser del exvoto. Lo que hay es un mensaje que proviene de experiencias siquicas y físicas transpuestas en símbolos bastante claros.

Otra vinculación que ofrece la pintura de Frida con el exvoto popular, está referida al soporte que emplea. Son varias las pinturas que realiza sobre lámina, las más significativas datan de 1931 y 1932. Para estos años ya había iniciado, ayudada por Diego, la famosa colección de exvotos que hoy en día puede verse en el Museo de Coyoacán. En los meses posteriores a su matrimonio pintó poco, o no pintó. Cuando volvió a tomar los pinceles, en Detroit, el año de 1931, las pinturas que realizó están pintadas sobre lámina y a partir de entonces usa indistintamente este material o tela sobre bastidor; todas las obras que pinta entre 1931 y 1933 son de pequeñas dimensiones y hechas sobre lámina. Se sabe de la existencia de varias de ellas. Un aparador de Detroit (1931), tres que se relacionan con el aborto que padeció en 1932 y 
DOI: http://dx.doi.org/10.22201/iie.18703062e.1976.45.1020

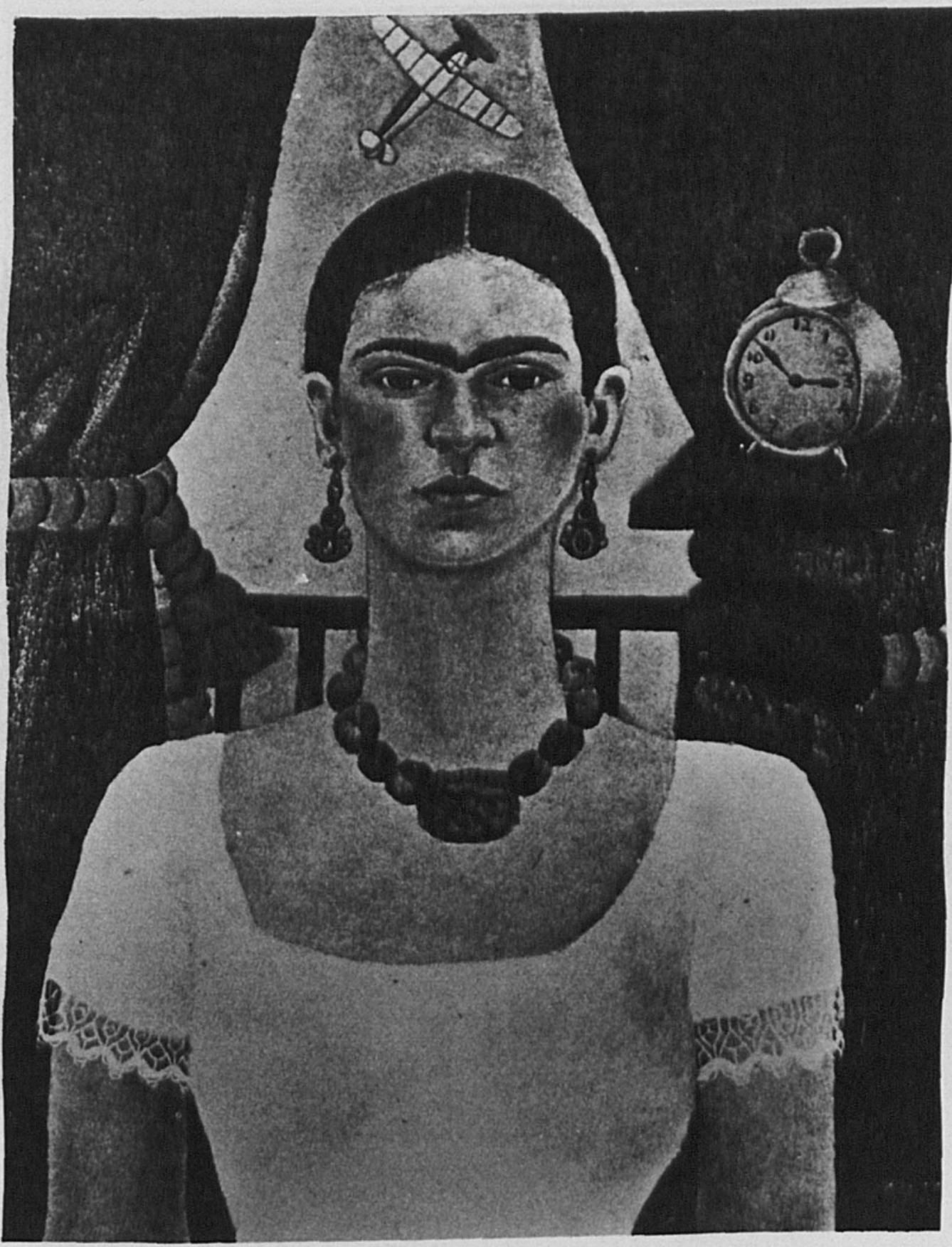

1. Autorretrato con aeroplano. 1929. Fotografía del INAH. 


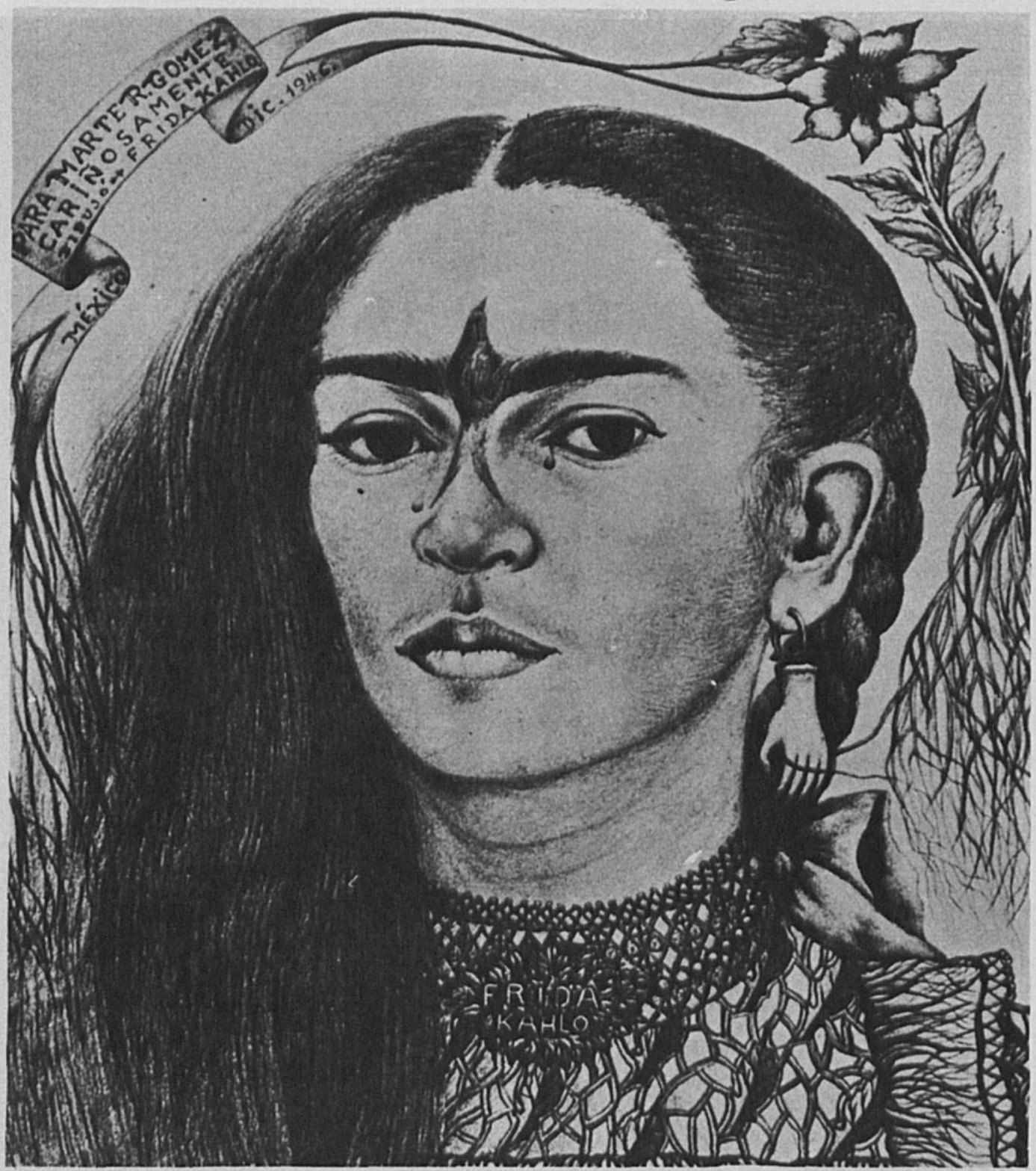

2. Autorretrato (dedicado a Marte R. Gómez). Dibujo, 1946. Fotografía de Guillermina Vázquez. 
DOI: http://dx.doi.org/10.22201/iie.18703062e.1976.45.1020

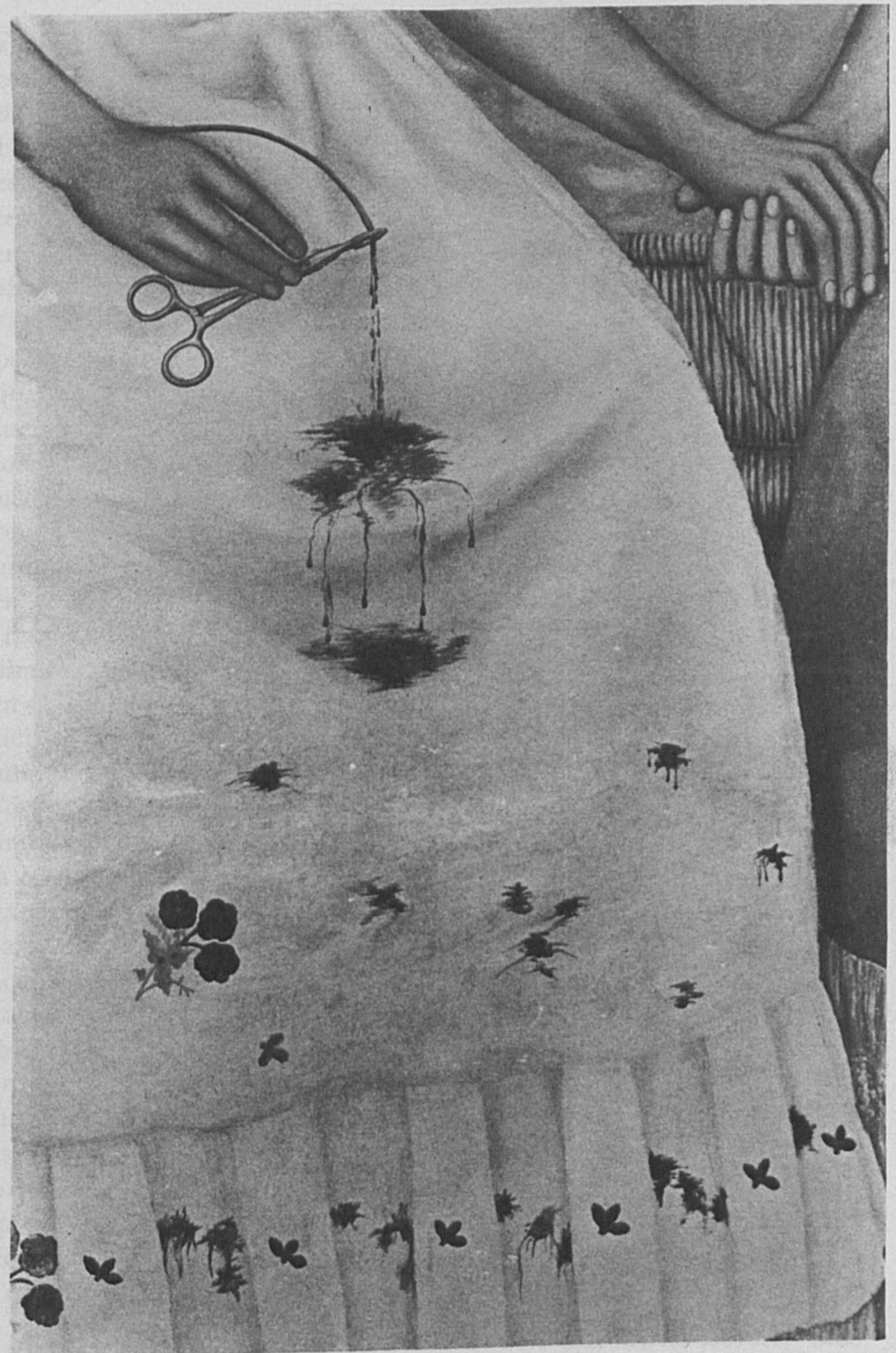

3. Las dos Fridas. 1939. Fotografía de Guillermina Vázquez. 
DOI: http://dx.doi.org/10.22201/iie.18703062e.1976.45.1020

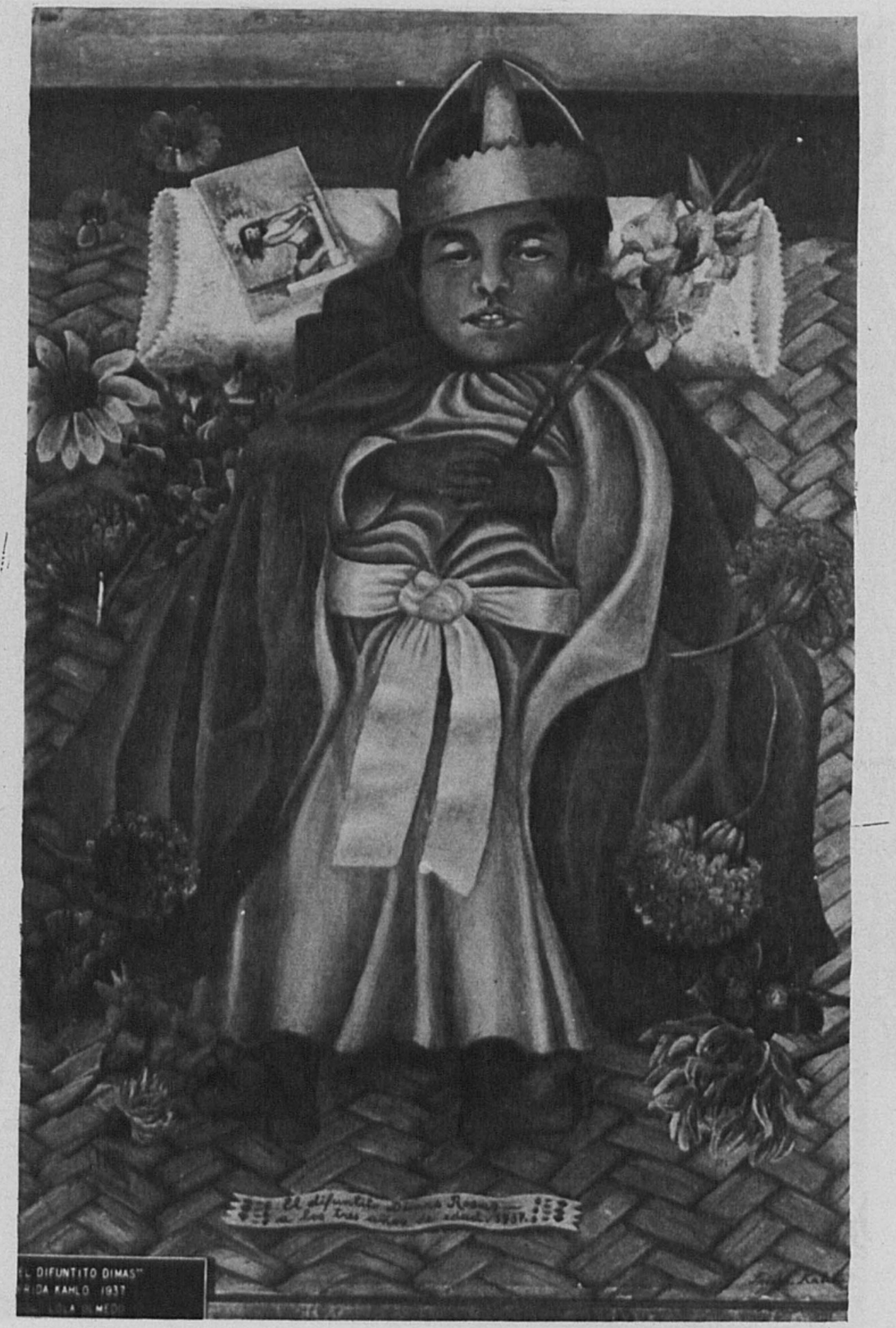

4. El difuntito Dimas. 1937. Fotografía del INAH. 
algunos autorretratos. Mac Kinley Helm ${ }^{5}$ percibe que en estas pinturas realizadas en Detroit "se implantan las semillas del desarrollo patológico de la pintura de Frida, sin que mano parisina alguna las haya sembrado". Esto es absolutamente cierto; no existen pinturas fantásticas o esotéricas'anteriores al viaje a los Estados Unidos. Inclusive un dibujo temprano (1926), que reproduce el accidente, ofrece datos sobre la forma en que aconteció, pero no presenta el afán obsesivo por destacar ciertos elementos como la sangre o las heridas.

En las pinturas de referencia, realizadas sobre lámina en 1932, lo que podría llamarse "popularismo" se encuentra combinado con imágenes que Frida ha tomado de sus libros de medicina y de anatomía. Esta fuente de su repertorio que está presente desde los inicios de su vida como pintora, lo que no es extraño si se recuerda que pretendía ser médico, multiplicará de elementos la mayor parte de sus obras subsecuentes al aborto. Es evidente que, por un lado, el hecho la desesperó profundamente y por otro, la hizo volver a consultar libros de medicina en aras de evaluar ella misma su estado. El cuadro titulado Hospital Henry Ford es característico de esta fase. Las figuras son de pequeñas dimensiones en relación al espacio libre que deja el plano del cuadro, en tal forma que el espacio aumenta en escala dada la falta de proporción que guardan las figuras con el todo. Frida yace en una cama sobre una sábana manchada de sangre. La cama se encuentra en el Hospital Ford, presumiblemente, pero en vez de que el plano horizontal quede limitado por dos diagonales para conformar la imagen de un recinto, la cama queda colocada aislada, en medio del piso, disociada de su contexto, tal y como acontece con obras típicamente surrealistas. Sin embargo, el lugar del acontecimiento sí está indicado, pues sobre la horizontal del plano se asoman los perfiles del mundo fabril de Detroit. La figura pequeña de Frida, desnuda, se encuentra rodeada de seis objetos que quedan ligados a ella por medio del cordón umbilical, son: un torno de hierro, alusión al mundo de las máquinas y a la vez instrumento de tortura, el modelo de una cadera humana como las que se usan en las lecciones de anatomía, otro modelo óseo que representa la pelvis femenina, un caracol, símbolo de vida, la figura de un feto de aproximadamente cuatro meses y una orquidea, recuerdo o transposi. ción de las que cada mañana recibía como regalo de Mrs. Esdel Ford. Todas estas figuras son exactamente del mismo tamaño y están pintadas

5 Mac Kinley Helm. Modern Mexican Painters. Dover Publications Inc., New York, 1974, p. 170. 
con minuciosidad, casi con preciosismo. Otras dos pinturas con el mismo tema son mucho más sangrientas, en una de ellas el cuerpo de Frida aparece decapitado con la cabeza entre las piernas. Las connotaciones médicas están presentes en todas y aparecen también en una litografía, del año de 1932, única obra que Frida realizó utilizando esta técnica.

Uno de los detalles que mejor ejemplifican la inspiración de Frida en sus conocimientos médicos se encuentra en el más conocido de sus cuadros: Las dos Fridas (1939), realizado para la exposición surrealista organizada por Wolfgang Paalen como vocero de André Breton en la Galería de Arte Mexicano. El conocimiento del instrumental quirúrgico, las pinzas de Peán y de la circulación arterial, inducen a Frida a crear un motivo en el que la sangre, como en otros cuadros, juega un papel primordial. La mano inerte de Frida controla la presión de la sangre en la arteria, que escapa formando una mancha en el vestido blanco a la altura de las rodillas, de allí gotea hasta confundirse con las flores rojas que ornan la parte inferior de la falda. La proclividad de Frida por representar sangre, culmina en un cuadro, sobre lámina titulado: Unos cuantos piquetitos, en el que las manchas de pintura roja rebasan el plano de la representación invadiendo el marco de madera.

Es sabido que el gusto por las representaciones sangrientas no sólo está presente en la pintura popular mexicana, sino que es una constante que aparece en diversas fases de la pintura colonial. Suponer que esta tendencia ancestral, brota de las entrañas del ser del mexicano y que por lo tanto de allí arranca este aspecto de Frida Kahlo, resulta demasiado simplista y en cierto modo viola la realidad, o la refleja mal. Si algo hay de eso, hay que aunarlo al temperamento morboso, y no sería aventurado decir "amarillista" de la pintora, que si bien es cierto que sufría intensamente con sus malestares físicos y morales, también lo es que encontraba cierta delectación en el sufrimiento, la muerte y la sangre. Basten dos ejemplos para confirmar lo que digo: la estupenda pintura realista que representa el cadáver de un niño de tres años: El difuntito Dimas (1937) y el regalo que pidió a un médico amigo suyo a través de una carta: un feto conservado en formol.

El difuntito Dimas es una pintura tan sofisticada y acabada en cuanto a factura, que se encuentra ya lejos de esas pinturas de 1929 en las que no pueden marcarse los. limites entre el deseo de expresión popular y la impericia. Sin embargo, este cuadro, por la temática, es profundamente 
popular. El estupendo oficio, la gama coloristica tan bien estudiada y ciertos detalles que pueden calificarse de hiperrealistas, hacen de esta pintura un típico ejemplo de obra "culta" que se funda en un tema netamente popular. No sólo es costumbre del pueblo tender al niño muerto como si fuera un pequeño santo, en este caso San José, sino que también es común que un artista anónimo, un pariente, o un amigo que entienda algo de pintura, dejen la imagen del "angelito" que al morir se ha convertido en objeto de veneración, durante el tiempo que dura el velorio. Si Frida Kahlo partió de una visión real para realizar su cuadro, o si utilizó un modelo vivo, eso no lo sabemos. Lo cierto es que cada elemento del cuadro: las flores, el gladiolo que el difuntito sostiene entre sus manos, la corona de latón, la estampa con "El señor de la Columna", revelan un conocimiento acucioso del tema que está tratando.

Otro tipo de vinculación que existe entre la pintura popular y Frida Kahlo es el carácter documental que tienen algunos de sus cuadros. Los elementos se concatenan aparentemente en forma disgregada, pero siempre en relación a su drama. Sin embargo no dejan ver el dolor, están apuntados con precisión y acaso también con sequedad. Frida está recostada en una cama del Hospital Ford después del aborto, pero su expresión es tranquila. Se encuentra una vez más postrada en otro lecho, alimentándose inútilmente con todos los beneficios que la naturaleza le trasmite por medio de un cuerno de la abundancia, sin que exista esperanza de salud; asi lo expresa el título del cuadro Sin esperanza, (1945), sin embargo su expresión no es doliente. En algunos autorretratos asoman dos decorativas lágrimas, aunque la expresión se mantiene impávida. Solamente en La columna rota (1944) logra trasmitir cierta impresión de dolor, más a base de lágrimas pintadas que mediante un cambio significativo en la expresión. "La efusión doliente y romántica que podría pedírsele a un ser tan padecido, no apunta nunca... y esto es eminentemente popular", afirma José Moreno Villa. ${ }^{2}$ La heroina del drama aparece en escena sin fundirse con la anécdota dramática, cpor voluntad propia, o por incapacidad? Parece ser que por lo primero; un exceso de expresión hubiera trastocado el carácter de la obra. Frida no es una pintora expresionista, como lo fue Orozco. Ni sus pretensiones ni su temperamento se prestaban para ello.

Quienes han comentado la obra de Frida Kahlo, siempre se han

6 José Moreno Villa. "La realidad y el deseo en Frida Kahlo." Novedades, México, 26 de abril de 1953. 
referido a su posible vinculación con el surrealismo. El que ha ido más lejos fue Raúl Flores Guerrero, al decir, en 1951, que "el surrealismo fue una meta y a la vez un paso en la historia del arte moderno, y el nombre de México, con el nombre de Frida, tiene su significación en ese momento de la plástica". 7 Seis años más tarde rectifica su punto de vista al realizar un estudio más pormenorizado sobre esta pintora. ${ }^{8}$ En esta segunda ocasión expresa lo siguiente: "Es el suyo un subjetivismo comunicativo, aprehensible artística y sentimentalmente... que no puede ser confundido con el subjetivismo cerrado del surrealismo bretoniano". Tanto Flores Guerrero como otros autores recuerdan que cuando Breton vio las pinturas de Frida, las etiquetó inmediatamente de surrealistas. ${ }^{~ F r i d a ~ c o n o c i o ́ ~ a ~ A n d r e ́ ~ B r e t o n ~ d u r a n t e ~ l a ~ v i s i t a ~ d e ~ e ́ s t e ~ a ~ M e ́ x i c o ~}$ en 1938, pero antes de eso había visto ya buenos ejemplos de arte surrealista durante su estancia en Nueva York. El mismo año que conoció a Breton expuso en la Galería de Julien Lévy, gran propulsor de esta corriente en Nueva York. Después de la muestra individual de sus obras se le presentó la oportunidad de asistir a la inauguración en París, febrero de 1939, de la exposición que André Breton montó en la Galería Renou et Colle, con 17 pinturas suyas, varios exvotos, objetos de arte popular y piezas prehispánicas. Todo el contingente de la exposición pertenecía al propio Breton, a Diego y a Frida. Durante ese viaje conoció y trató a varios representantes del grupo surrealista, entre otros a Wolfgang Paalen, que meses después vino a radicar a México junto con su esposa, Alice Rahon. Como dice Ida Rodríguez Prampolini, el saberse afín a una de las corrientes artísticas más en boga del momento, reafirmó a Frida en su tendencia a expresarse por la vía fantástica. Sin embargo, cabe aclarar que su obra más directamente surrealista Lo que el agua me ha dado, es anterior a las exposiciones de Nueva York y París. Esta pintura fue precisamente la que más impresionó a Breton.

Los nexos de Frida con el surrealismo no son intelectuales, su egocentrismo le impidió adherirse a cualquier tipo de programa. ${ }^{10}$ La

7 Raúl Flores Guerrero. "Frida Kahlo, su ser y su arte." Novedades, 10 de junio de 1951 .

8 Raúl Flores Guerrero, 5 pintores mexicanos. UNAM. 1957, p. 17.

$\because$ André Breton. Le Surréalisme et la peinture. Ed. Brentano, New York, 1945. Breton dedica un capitulo a Frida Kahlo. En él transcribe la primera impresión que le causaron sus cuadros.

10 Sus convicciones políticas tampoco fueron muy firmes. Esto se manifiesta en su actitud hacia el Partido Comunista Mexicano, basada más en consideraciones afectivas y convencionales de momento que en una verdadera postura. 
vinculación se da por coincidencia interna; Frida pintó lo que su yo le dictaba, y su yo era complicado, rico experiencias sui-generis y apto para expresarse por la vía del símbolo; no pintó el inconsciente porque en realidad no era muy introspectiva. Cierto es que no la animaron primordialmente preocupaciones estéticas o morales y en este sentido si se ajusta a la corriente bretoniana. También alcanza, en algunos casos, la belleza convulsiva, pero por accidente, puesto que no tendia a ese tipo de búsquedas; en esto resulta más genuina que los intelectualizados surrealistas.

He expresado atrás que es posible encontrar afinidades entre el modo de proceder del pintor nä̈ve y el proceso surrealista. También las hay entre esta corriente y la fantasia desbordante que manifiestan algunas creaciones del arte popular mexicano, derivadas de una fascinación ancestral por la metamorfosis y la muerte. Breton lo encontró así y por eso montó la exposición de souvenirs de México en la forma en que lo hizo.

Lo hasta aquí dicho permite concluir en la forma siguiente. Frida Kahlo eligió un tipo de expresión que se vincula a la expresión popular en parte porque asf le convenia y en parte por razones afectivas. Su lenguaje formal por lo común se nutrió de motivos populares; en varias ocasiones la obra es, integramente, recreación de un tema popular. Cuando adquiere madurez artistica, deliberadamente guarda reminiscencias naïve en algunos cuadros, principalmente en los que ejecuta bajo inspiración de los retablos o exvotos populares. Sus ligas con el surrealismo se dan por circunstancias personales que la hacen coincidir con esta corriente en algunas de sus obras, más que en otras, aun y cuando éstas queden también dentro del género fantástico. Dado que México cuenta con pocos adherentes formales a la corriente surrealista y en cambio con varios artistas que se han expresado, o se expresan por la via fantástica, es natural que el deslinde propuesto por Ida Rodriguez Prampolini sea dificil de aplicar a la obra de un artista en forma total. Es particularmente difícil en el caso de Frida, donde, como se ha visto, entran en juego otras influencias y sobre todo circunstancias peculiares que la mantienen como figura intensamente individualista. 